\title{
CONCEPTUAL APPROACHES IN THE REGIONAL SEGMENT ASSESSMENT THE ENERGY SECURITY STATE OF DECENTRALIZED TERRITORIES OF THE NORTHEAST OF RUSSIA
}

\author{
Stepan Reev ${ }^{1}$, Violetta Kiushkina², Boris Lukutin ${ }^{3}$ \\ ${ }^{I}$ Department of State Energy Policy Ministry of Energy of Russia \\ ${ }^{2}$ Chukotsk branch of the North-Eastern Federal University Scientific, Anadyr, Russia \\ ${ }^{2}$ Technical Institute (branch) of North-Eastern Federal University Scientific named after M.K. Ammosov, Neryungri, Russia \\ ${ }^{3}$ National Research Tomsk Polytechnic University Energy Engineering School, Tomsk, Russia
}

\begin{abstract}
In order to timely identify threats and risks to energy security and promptly respond to them and the dynamics of their change, the Energy Security Doctrine provides for the formation of a risk management system. The significant heterogeneity of the regions of the Russian Federation, including with a special specificity of the territories of the North and the Arctic zones and the predominance of decentralized energy supply in them, justifies the need for the formation of a regional segment of the assessment that provides for and takes into account these differences in detailing the sphere and the monitoring process itself. The paper presents proposals on the formation of the structure of a separate module of the regional segment for assessing the energy security of isolated areas, separate research modules and indicators for assessing decentralized power supply systems from the standpoint of ensuring energy security. One of the approaches to the formation of the structure of a single information space of the regional segment of the risk management system is proposed.
\end{abstract}

Regions of "Severny Zavoz", attributed to the North, differ significantly in terms of comfort of life and conditions of management. For these reasons, the zone is very heterogeneous in terms of economic and social development. The heterogeneity of the territories of the Far North regions, in particular the Far East region, from an energy point of view, characterizes a different degree and unevenness of the supply of fuel resources and a wide range of the level of energy security.

Analysis of energy supply in technologically isolated and remote territories of Russia is characterized by a number of negative indicators and trends that can provoke emergencies in fuel and energy supply systems. In such territories, with more than 100 thousand isolated settlements, the state of energy security is ensured by the proper functioning of decentralized energy supply complexes in conjunction with interconnected accompanying systems.

Based on the provisions of the Doctrine of Energy Security (DES) of the Russian Federation regarding decentralized territories, mainly located in the regions of the Russian North, a number of urgent tasks in terms of energy can be identified:

- ensuring reliable and sustainable provision of Russian consumers with energy resources of standard quality and services in the energy sector;

- ensuring the technical accessibility of the infrastructure of the fuel and energy complex for various groups of consumers and the possibility of providing them with services in the energy sector.
The territorial level comprehensively characterizes the state of energy supply to consumers on the territory of a subject or a federal district of the Russian Federation. The importance of interests and the weight of the characteristics of local energy zones and autonomous objects of electrification of the territories of the North makes it possible to single out the regional segment as a separate monitoring object with its own unified indicators (Figure 1,2) of the energy security assessment system.

In this regard, the task is to form a regional segment within the framework of the formation of a risk management system for the energy security of the Russian Federation (the creation of which is envisaged by the DES), providing for a significant socio-economic, climatic and other heterogeneity.

The degree of difference between the decentralized territories of the North-East and other territorial entities is great. The specificity of autonomous energy, leaving its mark, loses the possibility of reliable functioning in situations in which centralized energy remains survivable. They are not characterized by such indicators as the presence of unlimited transport links between energy zones for emergency mutual provision of fuel resources, electrical connections between decentralized power supply complexes (DECPS) within one zone and intersystem connections between zones, etc. At the same time, the influence of factors and conditions is maximized by extreme weather events and infrastructural isolation in the permafrost zone. The 
degree of detailed consideration of the peculiarities uncharacteristic for the rest of the territories of the Russian Federation in the choice of criteria for assessing the state, the direction of measures to improve energy security is relevant.

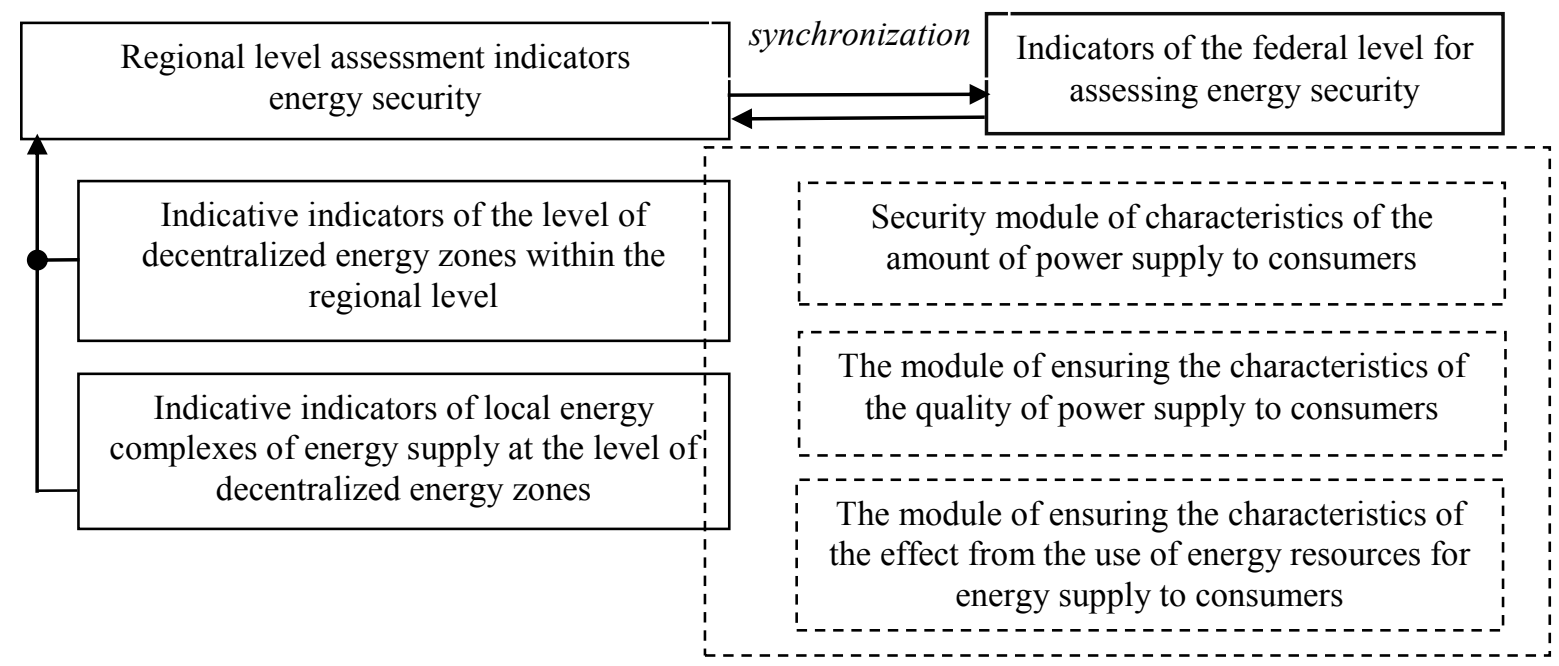

Fig 1. Proposals for the formation of a separate module of the regional segment for assessing the energy security of isolated territories

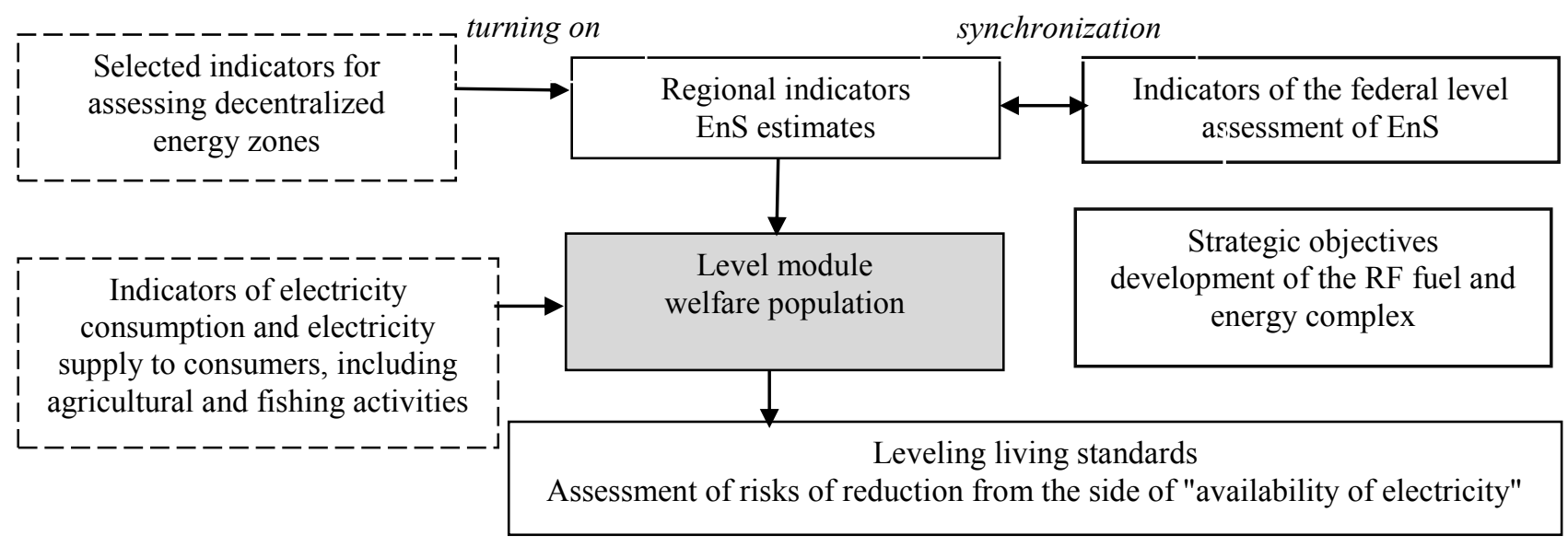

Resource modules
Indicators of the possibility of
developing the infrastructure of
the territory

Fig 2. Proposals for individual study modules and indicators for assessing decentralized power supply systems from the perspective of ensuring energy security 
For a timely and adequate response to emerging challenges and threats to energy security, improving the reliability and sustainability of the energy infrastructure, it is necessary to improve the quality, efficiency and expand monitoring aimed not only at identifying challenges, threats and risks to energy security, but also at their trends.

To this end, the Doctrine provides for the formation of an energy security risk management system (hereinafter RMS). The RMS provides for the participation of public authorities of the constituent entities of the Russian Federation within its competence. The inclusion of regional executive authorities in the composition of RMS subjects makes it possible to ensure a high-quality account of the regional peculiarities of the EnS, improve the quality of the information provided in the regional context and analyze the responsibility of the situation in the region within the framework of the distribution of powers. The consistency and harmonious balance of strategic planning documents in the energy sector makes it possible to quite clearly build the relationship between the basic principles of the nature of state activity and the mechanisms for implementing state policy in the field of ensuring energy and economic security with the allocation of guidelines for the regional component.

In accordance with this, the main tasks of the RMS at all levels are: monitoring, assessing and forecasting the state of energy security, as well as determining the resources necessary to prevent threats to energy security, reduce the likelihood of their implementation, as well as to minimize the consequences of their implementation.
In addition, the RMS is a tool that allows you to determine or clarify the tasks of the subjects of energy security, as well as planning measures to ensure energy security. To solve each task, the System must perform a number of functions according to its procedural structure. Energy security risk management is an integral part of government policy.

The specific feature of the characteristic threats of the territories under consideration necessitates a systematic analysis and, if necessary, adjustments to the components of the assessment of regional energy security. One of the key factors requiring close attention and detailed study is the strong relationship between energy and the economy of local energy supply systems in isolated remote areas of the North.

One of the basic modules of segments of any level is the process of collecting, processing, organizing and storing information about the current state of objects in the monitoring sphere and the dynamics of changes in events that affect the state of energy security.

These measurements must be synchronized with monitoring processes in the main areas of energy security, which cover 14 critical areas. These directions set its normative level. The values of the parameters are determined by the provisions of legislative and regulatory legal acts regarding these areas. Measurements include quantitative and qualitative characteristics of energy security and include both traditional energy security problems and environmental, socio-cultural and technological factors.

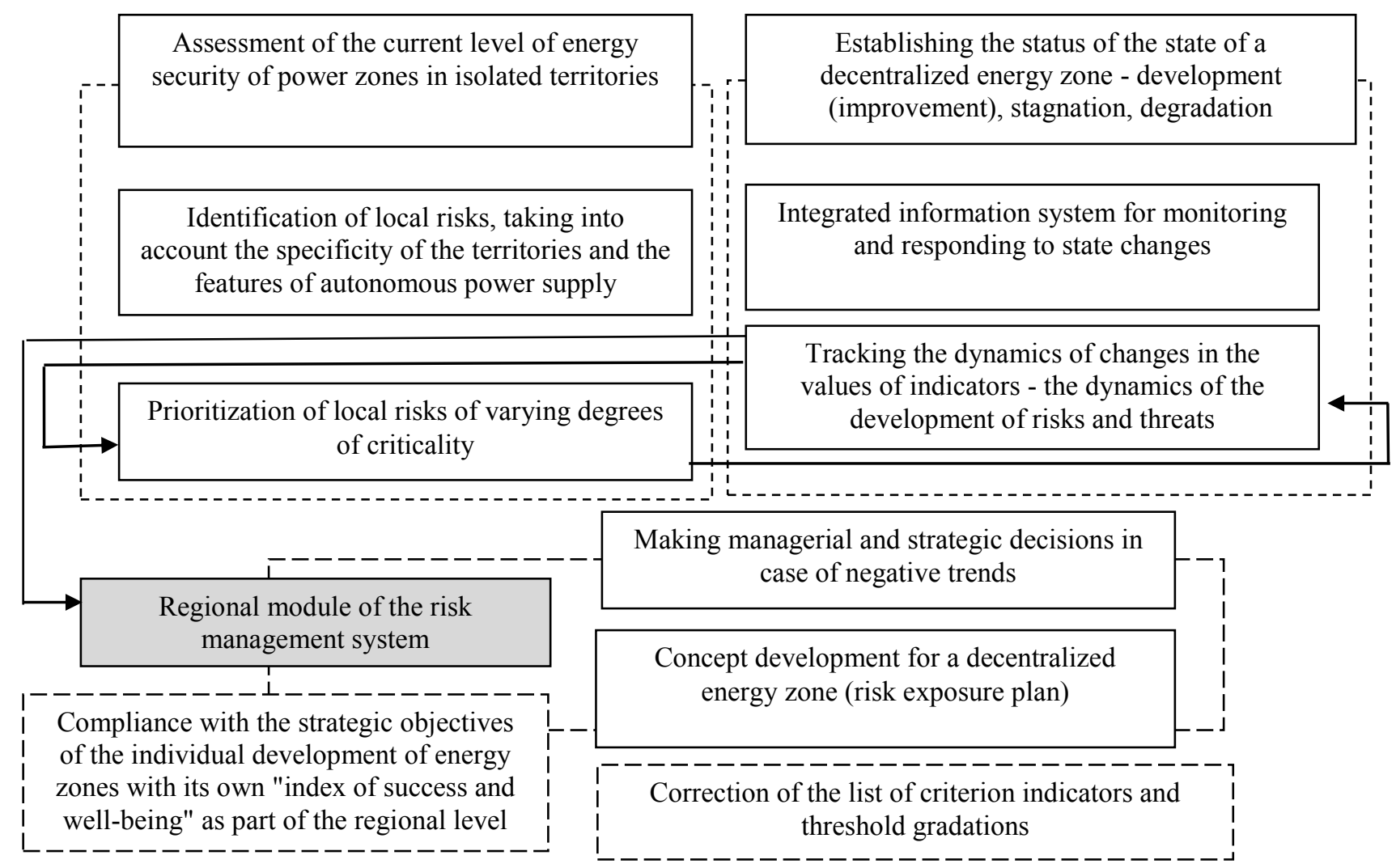

Fig 3. One of the approaches to the formation of the structure of a single information space of the regional segment of the RMS system 
The susceptibility of territories and objects of analysis (territorial or sectoral component of the structure) to energy security risks is realized in the characteristics of criterion indicators reflecting the degree of impact of threats inherent in each region.

Identification of local risks, taking into account the specificity of the territories and the features of autonomous power supply of decentralized areas (Figure 3 ). The study proposes a possible group of criterion indicators for assessing the regional level of energy security in decentralized areas, reflecting the degree of action of inherent and identified threats to the development and functioning of the energy sector, its subsystems and objects of the territories under consideration.

\section{Conclusions}

Continuous monitoring of the effectiveness of energy security management ways should be correlated with the actualization of the tasks of the strategic directions of the region's development, with the internal goals of socioeconomic development and indicators of the federal level in general and at the level of the constituent entities of the Russian Federation.

The implementation of the task will allow not only to solve the designated tasks, but also to create conditions for the growth of investments, technological renewal of the fuel and energy complex, the introduction of modern domestic technologies and equipment, as well as to train highly qualified personnel. 